\title{
Influence of Zirconium on the Recovery Process in Heat-resistant Al Alloys
}

\author{
Nada JAUKOVIC and Dragan PEROVIC ${ }^{1)}$
}

University of Montenegro, The Faculty of Metallurgy and Technology, Cetinjski put bb, 81000 Podgorica, Serbia and Crna Gora. E-mail: nada.jaukovic@cg.ac.yu 1) University of Montenegro, The Electrotechnical Faculty, Cetinjski put bb, 81000 Podgorica, Serbia and Crna Gora.

(Received on December 24, 2003; accepted in final form on March 14, 2004)

\begin{abstract}
Influence of zirconium on structure and properties of aluminium alloys used at elevated working temperature are given in this paper. By following changes in micro-hardness as a function of time for different temperatures and at different zirconium contents, activation energy of the recovery process, which served as an indicator of the creep resistance of the alloys, was determined. A mathematical model which enables to evaluate and predict required quality of alloys was also defined.
\end{abstract}

KEY WORDS: heat-resistant aluminium alloys; recovery; creep; activation energy; zirconium.

\section{Introduction}

On the basis of literature data ${ }^{1-6)}$ and previously obtained results $^{7,8)}$ it was concluded that the transition metals with relatively low solubility in solid state (manganese, chrome, zirconium, as well as lanthanides), added to the aluminium alloys can be used for strengthening of grains and sub-grain boundaries, due to precipitation in the form of fine dispersed particles. In this was, the recovery resistance can be increased and creep velocity decreased, which leads to high values of hardness parameters at raised working temperatures.

The basis idea was to find a method which, directly or indirectly, by following certain parameters, would enable obtaining of the relevant data on the basis of which it is possible to predict, with high accuracy, process at raised temperature, as well as to evaluate the quality and reliability factor of the manufactured alloys.

Since one of the heat-resistance criteria is yield creep, taking to account that difficulties in the recovery process means at the same time difficulties in the creep process, the accent was put on the investigation of the recovery process.

Calculated activation energy and relative recovery factor values were served as the indicators of the difficulties in development of the recovery process, i.e. zirconium effect on the creep resistance. In this papers, only the results relating to the activation energy of the alloys containing zirconium was presented.

\section{Experimental}

The initial material for the experiments was a heat-resistant alloy, type RR58 (AA2618), of a complex composition, produced by standard melting process, while zirconium was added in the form of $\mathrm{Al}-\mathrm{Zr} 5$ master alloy. Chemical composition of examined alloys is given in Table 1.

Casting process was followed by homogenization at the temperature of $510-515^{\circ} \mathrm{C}$ for $22 \mathrm{~h}$, and then by hot forging and cold rolling process. Recovery process was performed on all alloys at five selected temperatures, at a range of $150-350^{\circ} \mathrm{C}$, and for nine different time period.

\section{Results and Discussion}

\subsection{Activation Energy of the Recovery Process}

Activation energy of a recovery process in this paper was defined on the basis of analysis of the changes in microhardness with time, at different temperatures and with different zirconium contents. ${ }^{8)}$ Figure 1 shows time dependence of micro-hardness for the Alloy 1 (base alloy), shown in Table 1. Quantitative definition of the dependance of the recovery rate on time and temperature is usually followed by a complex procedure. In some cases, however, a simplified analysis can be applied. ${ }^{9)}$

Certain physical or mechanical properties (micro-hardness in this case) during recovery process of the deformed metal was analysed. According to Eq. (1)

Table 1. Chemical composition of the produced alloys [mas\%].

\begin{tabular}{lcccccc}
\hline & Cu & Fe & Ni & Mg & Si & Zr \\
\hline Alloy 1 & 2,10 & 0,96 & 1,21 & 1,28 & 0,30 & - \\
Alloy 2 & 2,15 & 0,91 & 1,20 & 1,26 & 0,29 & 0,0834 \\
Alloy 3 & 2,10 & 0,93 & 1,20 & 1,25 & 0,28 & 0,1763 \\
Alloy 4 & 2,10 & 0,91 & 1,18 & 1,24 & 0,28 & 0,244 \\
\hline
\end{tabular}




$$
d \Delta X / d t=K / t
$$

decrease or increase of velocity of any characteristics $(\Delta X)$ is inversely proportional to the recovery time $(t) .{ }^{10)}$ Parameter $K$ in Eq. (1) is constant for the given temperature and it depends on activation energy of the process $(Q)$, according to the Arenius equation. If $X_{\mathrm{d}}$ indicates value of micro-hardness after deformation, i.e. prior to the recovery process, micro-hardness after recovery is denoted by $X$, then the total change occurring during recovery can be expressed as

$$
X_{\mathrm{u}}=X_{\mathrm{d}}-X
$$

Parameter $X_{\mathrm{u}}$ is proportional to the volume error concentration $C$, occurring during deformation. ${ }^{9)}$ According to those statements, changes of the investigated parameters values with time can be given by

$$
\frac{d X_{\mathrm{u}}}{d t}=\frac{d C}{d t}=\frac{d\left(X_{d}-X\right)}{d t}
$$

Error annulment velocity, $d C / d t$, during recovery, depends on the error concentration $C$ and their mobility. If error annulment is considered as chemical reaction, the velocity can be written as follows:

$$
\frac{d C}{d t}=A C_{\mathrm{d}}^{n} \exp \left[-\frac{Q}{R T}\right]
$$

where $A$ is constant, $n$ is integer which is 1 for the reaction of first order, 2 for the reaction of second order, $Q$ is activation energy for the process, $R$ and $T$ have their usual meaning.

Results of Eqs. (2) and (3) combining and integrating be expressed as:

$$
\int \frac{d\left(X_{\mathrm{d}}-X\right)}{\left(X_{\mathrm{d}}-X\right)^{n}}=A \exp \left[-\frac{Q}{R T}\right] d t
$$

Thus, the final solution for the first-order reaction is:

$$
\ln \left(X_{\mathrm{d}}-X\right)-B=A t \exp \left[-\frac{Q}{R T}\right] d t
$$

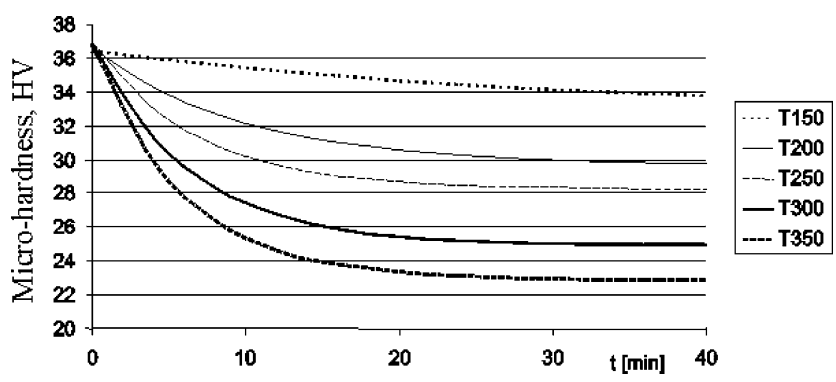

Fig. 1. Changes in micro-hardness for Alloy 1 .
Measuring the time, $t$, which is necessary for inducing always the same change $\left(X_{\mathrm{u}}=X_{\mathrm{d}}-X\right)$ at different temperatures, $T$, left side of the Eq. (5) becomes a constant:

$$
D=t \exp \left[-\frac{Q}{R T}\right]
$$

Then the solution is:

$$
\ln t=\ln D+\frac{Q}{R T}
$$

\subsection{Numerical Processing of the Experimental Results}

Isothermal curves of the recovery process were good basis for definition of the activation energy as function of alloying elements contents. For this purpose, modern software tools for tabular and graphic presentation of the experimental and computing data were used as a program package for the statistic analysis. The example of Alloy 1 illustrates a complete procedure of numerical and graphical data processing, performed on all the alloys. Only final results were presented.

Figure 1 illustrates graphically expressed the experimental results used to determine micro-hardness as function of time. It can be seen that the dependence of micro-hardness on time has exponential form, which was expected keeping in mind the nature of process. In order to attain the higher quality of the data processing and come to the more precise final results, each of the experimental curves was interpolated.

EViews3 program package, for data processing, statistical analysis, graphic presentation, estimation, prediction and simulation, was used for interpolation of the data through the average squared error minimization. This procedure was applied in two phases of the numerical data analysis.

In the first phase, experimental data were interpolated by exponential curve:

$$
H=C_{1}+C_{2} \exp \left(-C_{3} t\right)
$$

where $H$ is micro-hardness, $C_{1}, C_{2}$ and $C_{3}$ for the interpolation constants, $t$ is time interval.

Values of the interpolation curves coefficients for the Alloy 1 are given in Table 2.

In order to solve Eq. (5), prior calculation of time, needed to obtain always the same changes in micro-hardness at different temperatures, must be done. The analytical forms of all curves were obtained through the interpolation, which enabled easier fulfilment of this rather strict requirement.

Solution of the function given by Eq. (8), which represents the process in analytical form, for the constant microhardness $H_{1}$, can be done as:

$$
t_{1}=-\frac{1}{C_{3}} \ln \frac{H_{1}-C_{1}}{C_{2}}
$$

Table 2. Interpolation coefficients for Alloy 1

\begin{tabular}{ccccrrr}
\hline INTERPOLATION COEFFICIENTS & & & & $H=C_{1}+C_{2} \exp \left(-C_{3} t\right)$ \\
& & & & & \\
\hline & T150 & T200 & T250 & \multicolumn{1}{c}{ T300 } & T350 \\
\hline C1 & 32.73282 & 29.65133 & 28.24406 & 24.94041 & 22.87748 \\
C2 & 3.728633 & 6.962277 & 8.732063 & 11.9312 & 13.96849 \\
C3 & 0.032646 & 0.102076 & 0.150535 & 0.157167 & 0.172567 \\
\hline
\end{tabular}


Determination of the activation energy $Q$ and the constant $D$, demands matrix presentation of the time depending on reciprocal value of the temperature $(1 / T)$ and micro-hardness $\left(H_{30}, \ldots, H_{35}\right)$. The graphical presentation of those data was given in Fig. 2.

The activation energy $Q$ and the constant $D$ can be calculated from the slope of line (Fig. 2) and dependence given in Eq. (7).

Mathematical modelling, linear interpolation, minimization of error for the above mentioned data and application of the EViews3 program, resulted in the presentation of the dependent variables (Table 3), and the corresponding interpolation coefficients (Table 4).

On the basis of the coefficients $C_{1}$ and $C_{2}$ in linear interpolation curve

$$
\ln t=f(1 / T)
$$

lines which describe this dependence (Fig. 3) are defined as

$$
\ln t=C_{1}+C_{2} \cdot 1 / T
$$

Figure 4 shows corresponding 3D diagram of the time, temperature and micro-hardness dependence.

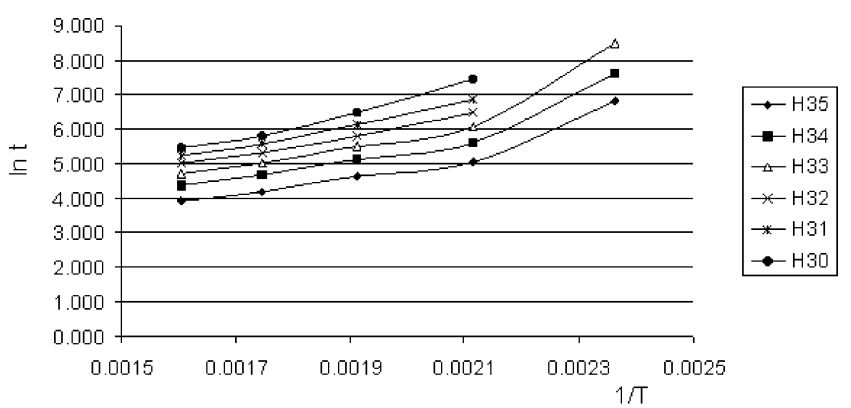

Fig. 2. Graphic presentation of $\operatorname{lnt}$ as a function $1 / T$ for Alloy 1 .
It is obvious that the increase of $\Delta H$ influences on increase of $Q$

Contrary to the existing literature data, ${ }^{7)}$ parameter $K$ of Eq. (1) is found to be not constant at the given temperature, but the variable which changes in inversely proportional way with activation energy.

Performing the identical procedure for all the manufactured alloys and calculating all previously mentioned parameters, resulted in a table indicating values of the activation energy for each of the alloys as shown in Table 5.

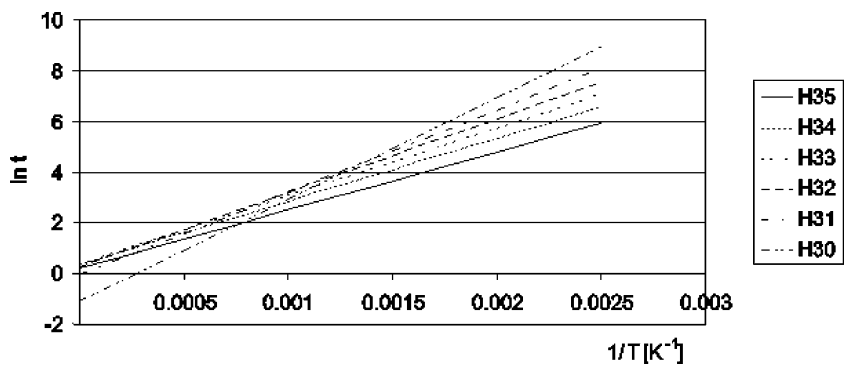

Fig. 3. Graphical presentation of $\ln t$ in function $1 / T$ for Alloy 1 .

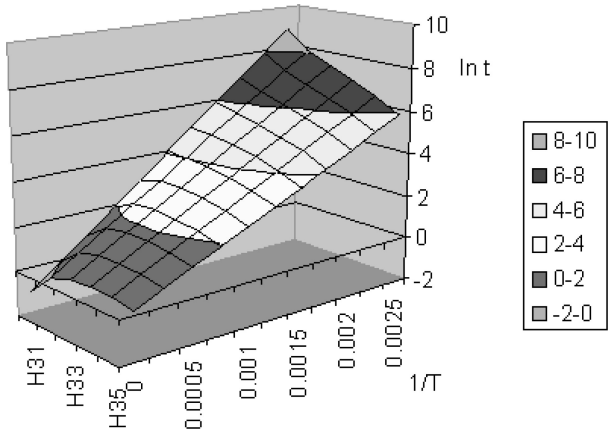

Fig. 4. 3D dependence diagram $\ln t-1 / T-H$.

Table 3. Presentation of the dependent variables.

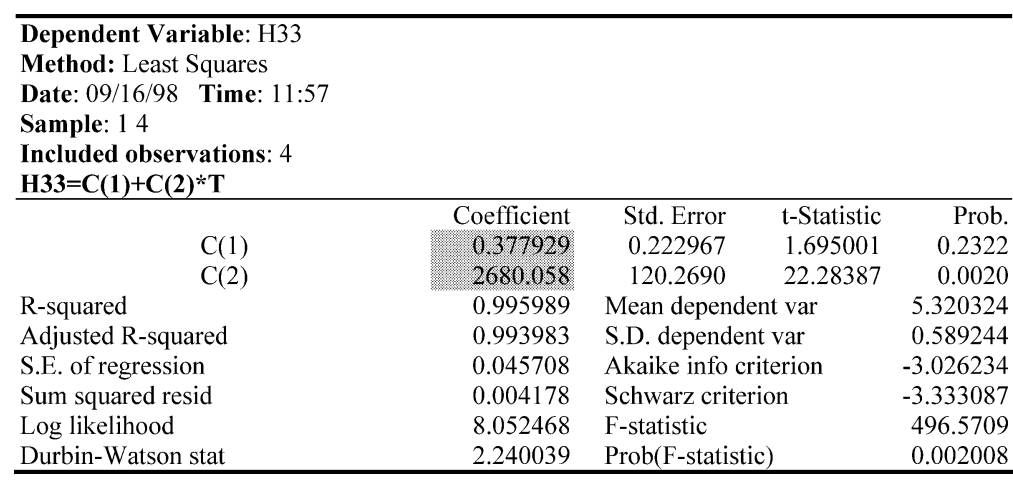

Table 4. Interpolation coefficients for Alloy 1

\begin{tabular}{lcccccc}
\hline \multicolumn{7}{c}{ INTERPOLATION $\ln \mathbf{t}=\mathbf{C 1 + C 2 * 1 / T}$} \\
\hline H35 & H34 & H33 & H32 & H31 & H30 \\
C1 & 0.205568 & 0.34442 & 0.377929 & 0.276154 & -0.05334 & -1.10555 \\
C2 & 2294.119 & 2492.345 & 2680.058 & 2910.698 & 3254.956 & 4013.156 \\
\hline
\end{tabular}

Table 5. Activation energy of the recovery process for the produced alloys.

\begin{tabular}{lcccc}
\hline & \multicolumn{4}{c}{ A L L O Y S } \\
\cline { 2 - 5 } & 1 & 2 & 3 & 4 \\
\hline$Q_{\text {mid }}[\mathrm{KJ} / \mathrm{mol}]$ & 31.34 & 47.43 & 51.00 & 75.72 \\
\hline
\end{tabular}


By analysing of the results, it was found that zirconium influences on increase of the activation energy from $3134 \mathrm{~kJ} / \mathrm{mol}$ to $7572 \mathrm{~kJ} / \mathrm{mol}$, depending on its content in the given alloys. Therefore, zirconium strongly affects the recovery process. The intensity of this influence is directly proportional to its content in the alloy.

Activation energy as function of alloy chemical composition and micro-hardness, given in form 3D diagram, is shown in Fig. 5. The non-linear dependence which confirms the previous statements is found.

\subsection{Mathematical Model}

Experimental results in Fig. 5 have been treated by interpolation models, on the basis of which corresponding graphic presentation were obtained.

Analysis shows that cubic interpolation, given by

$$
Q_{\mathrm{H}(34-30)}=C_{1}+C_{2} Z r_{(0-0.24 \%)}^{3}
$$

is in good accordance with the obtained results as shown in Fig. 6.

Further analysis of the cubic interpolation, introducing additional coefficients shown in Table 6, led to adequate mathematical model of activation energy dependence on chemical composition of the investigated alloys. Complete cubic interpolation shown in Fig. 7, can be expressed as
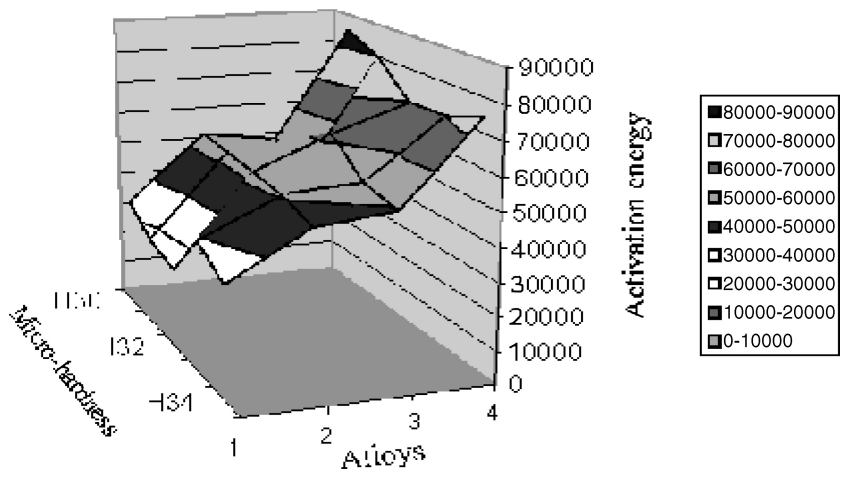

Fig. 5. Activation energy in the function of the chemical composition and micro-hardness for the alloys containing zirconium

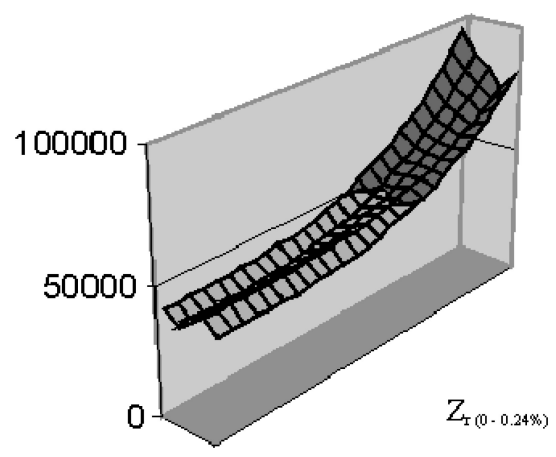

Fig. 6. Graphic presentation of the cubic interpolation. follows:

$$
Q_{\mathrm{H}(34-30)}=C_{1}+C_{2} Z r_{(0-0.24 \%)}+C_{3} Z r_{(0-0.24 \%)}^{2}+C_{4} Z r_{(0-0.24 \%)}^{3}
$$

Using an original program in MATLAB, the cubic polynom was developed and the following analytical expression is obtained:

$$
Z=a_{1}+a_{2} x y+a_{3} x y^{2}+a_{4} x y^{3}
$$

Where $a_{1}-a_{4}$ are the coefficients of interpolation area, $x$ is micro-hardness, $y$ is zirconium content, $Z$ is required activation energy.

Graphic interpolation of this dependence is shown in Fig. 8. It can be seen that the mathematical model is in good accordance with the experimental results shown in Fig. 5. This means that the choice of the cubic interpolation is highly reliable for the simulation of the recovery process.

On the basis of the presented results and theoretical considerations, it can be concluded with a high probability that the applied model is valid within a wider concentration interval and different chemical compositions.

Therefore it should be taken into account that the manufactured alloys are very complex system, which are, due to numerous influential factors and complexities in quantita-

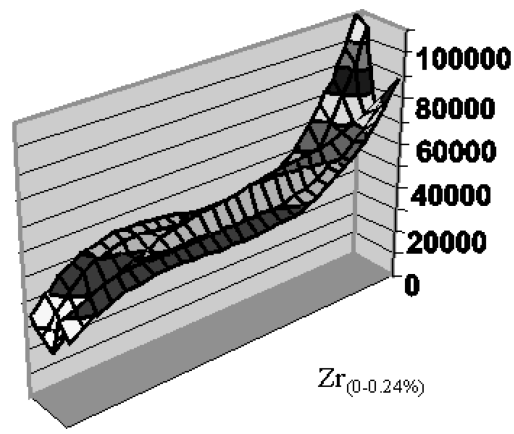

Fig. 7. Graphic presentation of the complete cubic interpolation.

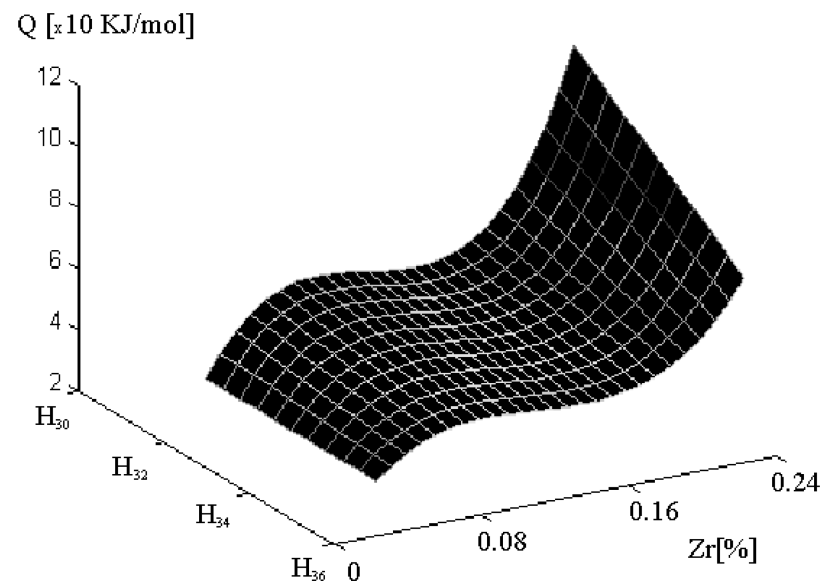

Fig. 8. 3D mathematical model.

Table 6. Interpolation coefficients for Alloy 1.

\begin{tabular}{lccrrr}
\hline & $\mathbf{Q}_{\mathbf{H 3 4}}$ & $\mathbf{Q}_{\mathbf{H 3 3}}$ & $\mathbf{Q}_{\mathbf{H 3 2}}$ & \multicolumn{1}{c}{$\mathbf{Q}_{\mathbf{H 3 1}}$} & \multicolumn{1}{c}{$\mathbf{Q}_{\mathbf{H 3 0}}$} \\
\hline $\mathrm{C} 1$ & 33723.35 & 39269.24 & 24199.54 & 27061.7 & 33365.38 \\
$\mathrm{C} 2$ & 424858.8 & 346214.3 & 555336.5 & 901729.5 & 702991.3 \\
$\mathrm{C} 3$ & -4269816 & -3375826 & -3138578 & -9445542 & -7399078 \\
$\mathrm{C} 4$ & 13332914 & 10276150 & 6717425 & 27507360 & 22383982 \\
\hline
\end{tabular}


tive determination of the recovery rate, dependence on time and temperature, and consequently very complex system for an analysis. In spite of that, the applied model gave satisfactory data for its further use.

\section{Conclusions}

- Activation energy of the recovery process at a given temperature is a function of micro-hardness. Parameter $K$ is not constant at a given temperature, but a function of micro-hardness. Parameter $K$ is inversely proportional with activation energy.

- Activation energy of the recovery process is directly proportional to the quantity of zirconium content.

- Zirconium influences on decrease of recovery rate, i.e. delays creep process and in this way directly influence on increase of the required mechanical properties at the elevated working temperature.

- Presented mathematical model can be used for estimation and prediction of some mechanical properties of wrought heat-resistant $\mathrm{Al}$ alloys.

\section{REFERENCES}

1) J. E. Hach: Aluminium-Properties and Physical Metallurgy, American Society for Metals, Ohio, (1984), 424.

2) R. E. Read-Hill: Physical Metallurgy Principles, D. Van Nostrand, New York, (1973), 920.

3) Physical Metallurgy, ed. by R. W. Cahn, North-Holland Pub. Co., Amsterdam, (1985), 660 .

4) K. Kawakami, M. Okuno, K. Ogawa, M. Miyauchi and K. Yoshida: Furukawa Review, No. 9, (1991), 81.

5) B. Y. Zong and B. Derby: Acta Mater, 45 (1997), 41

6) I. N. A. Oguocha and S. Yannacopoulos: J. Mater. Sci., 31 (1996), 3145 .

7) N. V. Jaukovic: M. S. Thesis, Podgorica, (1993), 113.

8) N. V. Jaukovic: Ph. D. Thesis, Podgorica, (1998), 142.

9) Dj. Drobnjak: Physical Metallurgy, Belgrade, (1990), 401.

10) I. I. Novikov: Teorija termicheskoj obrabotki metallov, Metallurgija, Moskva, (1986), 480. 